Revista Destaques Acadêmicos, Lajeado, v. 10, n. 4, 2018. ISSN 2176-3070

DOI: http://dx.doi.org/10.22410/issn.2176-3070.v10i4a2018.2042

http://www.univates.br/revistas

\title{
A CIDADE DISPERSA E SUA INFRAESTRUTURA COMO CONSEQUENNCIA: UM ESTUDO PARA A CIDADE DE LAJEADO/RS
}

\author{
Fernanda Daroit Lappe ${ }^{1}$, Alexandre Pereira Santos ${ }^{2}$
}

\begin{abstract}
Resumo: Este artigo apresenta uma reflexão sobre o padrão de urbanização do município de Lajeado/RS a partir da relação entre densidade e infraestrutura. Ele apresenta revisão sobre os parâmetros de qualidade de infraestrutura segundo a literatura científica e boas práticas de planejamento. Adicionalmente, como método de estudo, apresenta análises das infraestruturas indispensáveis à qualidade de vida, suscitando uma reflexão acerca dos contrastes encontrados nos bairros do município. Ademais, observa-se, na cidade, uma malha urbana dispersa e fragmentada, que concentra contingentes populacionais em porções relativamente pequenas, quando comparadas à sua área total. Percebese que a infraestrutura encontrada é proporcional à densidade populacional de cada bairro e que a forma de crescimento da cidade tem reflexo direto em sua infraestrutura e sistema de mobilidade.
\end{abstract}

Palavras-chave: Densidade urbana. Dispersão urbana. infraestrutura urbana; transporte coletivo.

\section{INTRODUÇÃO}

A forma das cidades é crescentemente associada à disponibilidade de serviços e equipamentos públicos às populações urbanas (ACIOLY; DAVIDSON, 1998; VARGAS, 2003), trazendo impactos diretos à qualidade de vida. Na medida em que as cidades crescem, especialmente a partir do século XX, percebe-se padrões cada vez mais dispersos de urbanização (REIS, 2006; VILLAÇA, 2011), que podem trazer impactos negativos na capacidade das pessoas acessarem estes serviços e infraestruturas, ou criarem dependência de deslocamentos veiculares frequentes. Além disso, pesquisas recentes têm apontado impactos da densidade na vitalidade urbana (NETTO, 2016;

1 Universidade do Vale do Taquari, acadêmica do curso de Arquitetura e Urbanismo

2 Universidade do Vale do Taquari, professor do curso de Arquitetura e Urbanismo. Arquiteto e Urbanista, mestre. 
NETTO; VARGAS; SABOYA, 2012) e mesmo na saúde das populações urbanas (AMARO, 2016).

Nesse contexto, o presente artigo apresenta considerações sobre os conceitos e impactos da densidade urbana e sua relação com as infraestruturas instaladas para a cidade de Lajeado/RS, cidade localizada na região centro oriental do Estado do Rio Grande do Sul com $90,611 \mathrm{~km}^{2}$ de extensão e população (estimada) de 82.951 habitantes (IBGE, 2018), ilustrada na Imagem 01, abaixo.

Imagem 01 - Mapa do município de Lajeado dividido em bairros e seus limites geográficos

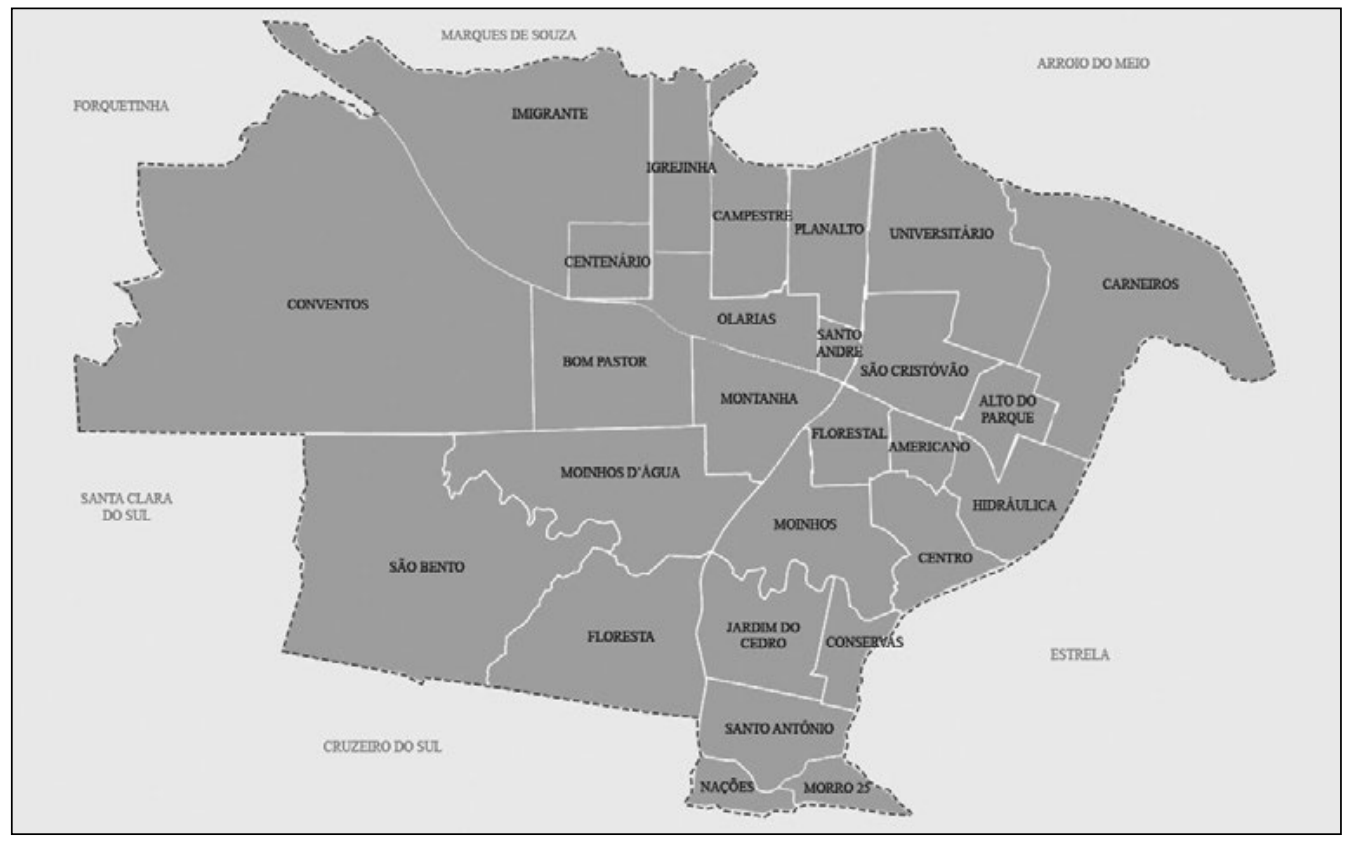

Fonte: Dos autores (2018).

Para realizar esta avaliação, observam-se os bairros do município a partir de sua densidade demográfica bruta, cotejando esta com a oferta de infraestruturas, tais como qualidade do sistema viário, oferta de transporte coletivo e iluminação pública. A partir desta análise, surge a importância de observar modelos de urbanização atuais, como cidades compactas e dispersas, além de conceitos de densidade e mobilidade urbana associados a estes modelos. Propõe-se também a ponderação a respeito dos habitantes das diversas regiões urbanas e do direito à cidade ofertado - ou sua carência - aos mesmos, especialmente no que se refere a relação da densidade e acesso às infraestruturas e serviços urbanos.

Discute-se também sobre as principais causas e consequências da fragmentação urbana observada no município, sendo abordados os fenômenos 
que geram estas descontinuidades, e suas interferências na vida cotidiana dos moradores da cidade. Observam-se as influências da densidade nas desigualdades sociais e na redução de acessibilidade e, em última análise, do direito à cidade. Ao fim, sugerem-se aprofundamentos e continuidades aos estudos da densidade no município, especialmente no que tange outras infraestruturas e na promoção do transporte público.

\section{SOBRE A CIDADE DISPERSA}

Cidades compactas e dispersas são temas urbanos recorrentes nos dias de hoje, porém sua conceituação marca a história do urbanismo há mais de um século. Bruegmann (2005) relata que na Roma Antiga já haviam bairros construídos além das muralhas, sendo que esse distanciamento era estratégico a para fugir das imposições das autoridades.

Já Frederich Engels (1974), um dos pioneiros na pesquisa sobre a realidade urbana da Europa do século XIX, descreve a situação vivida na cidade de Manchester, na Inglaterra. Engels retrata o fenômeno da segregação, tanto social quanto urbana, decorrente do modelo socioeconômico da época. Para ele, as grandes cidades sempre apresentam "bairros de má reputação", onde reside a classe operária e, consequentemente onde se localizam as piores casas. Critica o teórico: "A própria cidade está construída de uma maneira tão peculiar, que podemos habitá-la durante anos, sair e entrar nela cotidianamente, sem nunca entrevermos um bairro operário." (ENGELS, 1974, p. 80).

Atualmente, contudo, a dispersão é um fenômeno crescente nas cidades de todas os partes (REIS, 2006) que restringe o direito à cidade de muitos. Silva (2013) caracteriza cidades dispersas como a extensão da configuração do tecido urbano que conformam núcleos territorialmente descontínuos. Janoschka (2002) adapta este conceito para a América Latina e observa o impacto do modelo, indicando tendência de agravamento da dispersão para as próximas décadas, acompanhado de aumento da segregação socioespacial. No hemisfério norte, este fenômeno também é observado, alimentado especialmente por consumo crescente de terra para cada domicílio no sprawl ${ }^{3}$, apesar da estabilização do crescimento da população (LEE, 2007; PARESI et al., 2016).

Em contrapartida, segundo Malenronka (2018) cidades compactas possuem alta densidade populacional e intensidade de usos comerciais, de serviços e infraestruturas. Ao passo que se costuma imaginar este fenômeno a partir de arranha-céus, em realidade observam-se grandes densidades até mesmo nas favelas, por exemplo, onde não há verticalização intensa (ACIOLY; DAVIDSON, 1998).

3 Espalhamento da ocupação urbana, caracterizado por enormes extensões de áreas residenciais organizadas por redes de estradas e centros comerciais de grande porte, com baixíssimas densidades e grandes extensões. 
Ao se considerar, portanto, a forma das cidades e a verticalização a fim de promover aumento na densidade populacional, deve se observar os impactos que a construção de grandes edifícios acarretam, como na perda de iluminação solar e ventilação adequada do entorno, além das notáveis perdas visuais associadas. Ao observar diversas os padrões de urbanização mundiais, Acioly e Davidson (1998) indicam que densidade populacional, em realidade, é bastante relativa a configurações sociais e culturais, além de depender diretamente da oferta de infraestrutura, podendo ser obtida em diversas configurações urbanas. Uma boa ilustração deste fato pode ser feita entre duas metrópoles densas ao redor do mundo: Paris e Nova York. Esta com 27.812 hab. $/ \mathrm{km}^{2}$, aquela com $21.616 \mathrm{hab} . / \mathrm{km}^{2}$, ou seja, densidades populacionais relativamente próximas, mas morfologias e escalas de urbanização muito distintas.

Na América Latina, o quadro é bastante diverso, com combinações de alta densidade e grande dispersão e relações entre centros elitizados e bem providos de infraestrutura, com periferias esparsas e carências generalizadas (ABRAMO, 2001; CALDEIRA, 1997; VILLAÇA, 2011).

Ojima e Marandola Jr. (2016) qualificaram a dispersão urbana em duas dimensões: a auto segregação e a periferização. Para eles, a primeira é uma escolha do cidadão, que possui condições financeiras de morar longe dos grandes centros urbanos. Estes geralmente residem nos grandes condomínios fechados, destinados exclusivamente à população de alta renda, ou nos típicos subúrbios norte-americanos, com grandes casas isoladas nos lotes, conforme descrito por Malenronka (2018). Já a segunda dimensão abordada pelos autores trata da população de baixa renda, que só consegue localizar-se em terrenos afastados do centro, ou em locais com fragilidades ambientais graves (SANTOS et al., 2017). Para esse grupo social a segregação é mais uma imposição do que uma escolha.

Botelho (2012) discrimina os seis principais elementos motivadores ao modelo disperso urbano. A primeira causa apontada é a naturalista: moradores de regiões centrais buscam espontaneamente lugares mais afastados, buscando menos poluição, custos mais baixos e espaços maiores. A causa tecnicista, que possibilita a mobilidade dos habitantes até regiões mais centrais, onde há as áreas de trabalho, consumo e lazer.

Além destes, o terceiro ponto abordado por Botelho (2012) é o american way of life -os subúrbios anteriormente mencionados. Descrita como culturalista, essa causa remete à busca por vizinhanças mais homogêneas. Outro motivo que atrai público para fora de áreas centrais é o economicista. Esse é a resposta imediata à especulação mobiliária, resultado da busca pelo bem individual de vendedores e compradores.

$\mathrm{O}$ autor descreve ainda o fator estatista, que responsabiliza o governo pela concessão de subsídios aos moradores das periferias. Além disso, é tarefa do Estado "a oferta de infraestrutura viária que garantiria a acessibilidade às áreas mais afastadas dos centros tradicionais e a construção de conjuntos 
habitacionais para os mais pobres em áreas distantes do centro", retrata Botelho (2012).

Por fim, a última causa é fruto da oportunidade de escolha dos membros da sociedade. O sistema político da democracia dá essa liberdade às famílias, que conseguem se manter longe de centros urbanos com meios de transporte próprios.

\section{IMPACTOS DA DISPERSÃO NO CONTEXTO URBANO}

É notável que o modelo de urbanização dispersa tem grandes demandas de energia e recursos naturais, além de ser desvantajoso para o governo (SPOSITO, 2014 apud. NASCIMENTO JÚNIOR, 2017). Isso se deve ao fato de que malhas urbanas descontínuas elevam os custos do transporte coletivo, e exigem obras mais extensas em infraestrutura viária, de iluminação, energia, abastecimento de água e produção de alimentos (NASCIMENTO JÚNIOR, 2017).

Sposito (2014 apud. NASCIMENTO JÚNIOR, 2017) ainda afirma que cidades que possuem o modelo disperso possuem rupturas e descontinuidades em sua malha urbana, e acabam reconfigurando sua distribuição de usos residencial, industrial, comercial e de serviços. Esse novo arranjo espacial transforma profundamente o dia a dia das pessoas e a maneira como estas se relacionam com a cidade, ampliando a especialização das atividades e a segregação entre as classes sociais.

A segregação socioespacial é, sem dúvida, um grande problema reforçado pela dispersão. Para Reis Filho (2012), o problema tem início na segunda metade do século XX, quando o Brasil se tornou um país majoritariamente urbano e metropolitano. Segundo o autor, o país não conseguiu atender às demandas por habitação e serviços urbanos, sendo que ainda hoje enfrentamos problemas socioeconômicos e ambientais em larga escala.

Quem mais sofre com esta urbanização veloz e súbita - que careceu de um profundo planejamento - são os mais pobres, que muitas vezes não encontram oportunidades na cidade formal e acabam compondo as habitações informais. Moura (2006) reforça que há séculos as moradias populares são implantadas em espaços urbanos precários, enquanto Abramo (2001) sugere que estas desigualdades são elementos essenciais das dinâmicas de crescimento urbano latino-americanas.

A mobilidade também é um dos pilares para o bom funcionamento e organização das cidades e sua relação com a segregação tem impactos importantes no direto à cidade. Ojima e Marandola Jr. (2016) discorrem sobre a relação do uso do automóvel com a dispersão urbana. De acordo com os autores, a disponibilidade de veículos próprios e de vias são fatores que influenciam na formação de cidades extensas, especialmente a partir dos anos 1980 no Brasil. Entretanto, esta expansão impacta o custo do solo, e aumenta 
as distâncias de deslocamento mesmo para aqueles que não têm acesso à automóveis particulares e dependem do funcionamento do transporte público.

Em contraponto e de acordo com as premissas do Desenvolvimento Orientado ao Transporte Sustentável (DOTS, como definido pelo WRI em EVERS et al., 2018) um dos benefícios de cidades compactas são as conexões com a rede de transporte coletivo. Isso acontece porque cidades mais densas possuem linhas de ônibus mais baratas e eficientes, já que o custo dos sistemas de transporte coletivo é proporcional à distância em que se estende a malha urbana. Tanto o setor público quanto o privado acabam arcando com os custos ocasionados pela dispersão através do aumento no consumo de combustível (SMITH; DOHERTY, 2006) e da maior demanda por obras de infraestrutura e serviços públicos (NASCIMENTO JÚNIOR, 2017).

Usualmente, quanto mais dispersa for a malha urbana, menos atrativo é seu sistema de transporte coletivo, que não consegue conciliar frequência nas linhas, conforto dos ônibus e paradas, tempo de viagem e regularidade do transporte com um preço condizente com o que a população possa pagar.

Tanscheit (2016) também reflete sobre as consequências do modelo urbano disperso. Segundo a autora, os benefícios trazidos pelo mais extenso desenvolvimento de infraestrutura acabam sendo direcionado somente às pessoas diretamente atendidas pelo sistema - os moradores periféricos.

Outro impacto proveniente da fragmentação urbana é a destruição do meio ambiente, visto que mais áreas verdes são devastadas para ocupação humana, conforme o demógrafo Felipe Monteiro (2015). Além disso, o autor cita a contaminação do ar pelos gases nocivos à saúde da população, oriundos da maior quantidade de veículos transitando.

Por fim, pode-se incluir como produto da morfologia urbana em análise a implicação no quadro de saúde dos habitantes. O incentivo ao uso de transportes individuais em larga escala promove a diminuição de caminhadas diárias (GARDEN; JALALUDIN, 2009), prática de atividades físicas e a utilização de transportes alternativos para locomoção, como a bicicleta. Estas consequências têm aumentado as taxas de obesidade e sedentarismo na maior parte do mundo. Em decorrência deste quadro, há a formação de uma sociedade menos produtiva e ainda mais gastos com saúde pública, conforme Amaro (2016).

\section{ANÁLISE DO MUNICÍPIO DE LAJEADO/RS}

A partir das considerações teóricas de base apresentadas, cabe considerar a realidade local mediante estudo empírico sistemático. Este capítulo busca apresentar a análise do município de Lajeado/RS quanto às questões de distribuição populacional, morfologia urbana e infraestruturas, avaliando a situação presente desde os atributos da forma urbana e observando assimetrias internas da área urbana. Esta reflexão busca, em última medida, 
avaliar a qualidade da urbanização do município no que se refere a sua forma urbana e infraestruturas.

Lajeado é uma cidade localizada na região centro oriental do Estado do Rio Grande do Sul. Sua extensão territorial é de 90,611 km², dividida em 27 bairros. Conforme estimativas do IBGE (2017), para o ano de 2018 a população é de 82.951 habitantes. Praticamente todo o território do município é urbano e, em 2010, havia somente 265 pessoas vivendo em áreas rurais, o correspondente a apenas $0,37 \%$ da população total.

A população nos últimos anos apresenta um crescimento de $1,92 \%$ ao ano em relação a 2007 (IBGE, 2010). Com densidade populacional de 793 hab./ $\mathrm{km}^{2}$, Lajeado ocupa a décima primeira posição no ranking demográfico dos 497 municípios gaúchos (IBGE, 2010).

O Gráfico 01 permite notar que o crescimento da cidade foi superior à média estadual e à microrregião de Lajeado-Estrela nas duas últimas décadas. Além disso, a densidade média é cerca de 20 vezes maior que a densidade média ${ }^{4}$ do Rio Grande do Sul $\left(39,79\right.$ hab. $\left./ \mathrm{km}^{2}\right)$, conforme dados da Prefeitura Municipal de Lajeado (2018).

Gráfico 01 - Taxa geométrica média de crescimento populacional anual 19912010

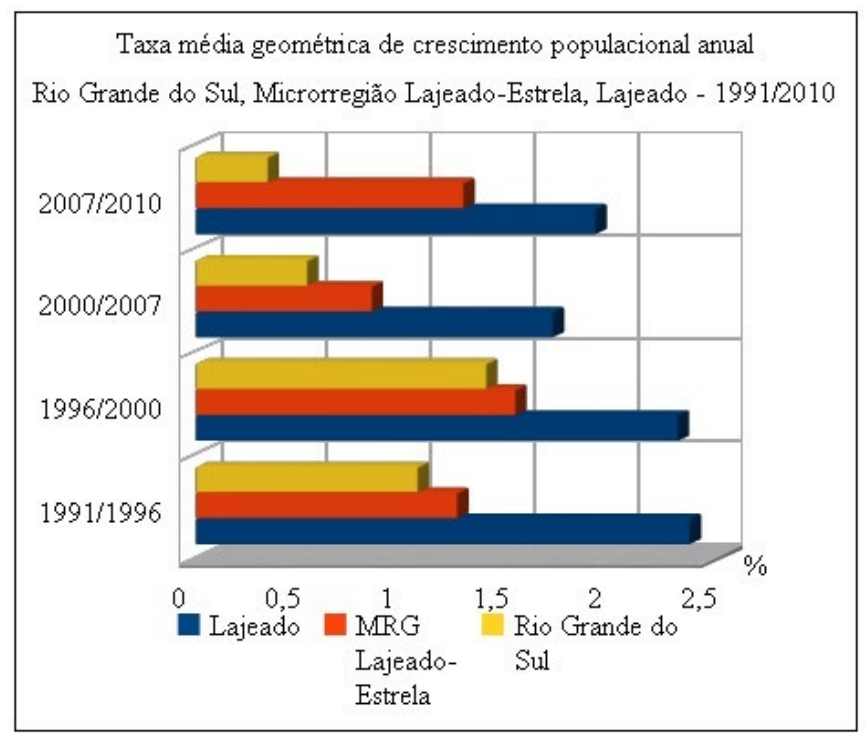

Fonte: Prefeitura municipal de Lajeado (2018), a partir de IBGE (2010).

4 Para este artigo, será considerada a densidade populacional bruta, de forma a integrar análises intra urbanas com outras escalas. Explorações posteriores podem debruçar-se sobre a densidade líquida de sua urbanização, a partir de dados mais detalhados dos que os analisados aqui. 
A recomendação para a mínima densidade de um crescimento urbano saudável é de 10.000 hab. $/ \mathrm{km}^{2}$, conforme diretrizes de desenvolvimento urbano "verde" e saudável do CDBC (BUSCH; HARVEY; HE; HUANG, 2015). Para este valor, utiliza-se a relação da população residente e a área ocupada pela mesma, sem descontar vias, áreas verdes e demais espaços públicos. Desta forma a cidade compacta permite melhor qualidade de vida a seus habitantes e ao meio ambiente, conforme visto anteriormente. Entretanto, é notável o quanto a densidade ideal é distante do cenário urbano lajeadense e, em geral, do Brasil. Há apenas cinco cidades brasileiras que atendem a essa indicação, sendo todas localizadas no estado de São Paulo e Rio de Janeiro (IBGE, 2010).

Conforme estimativas do IBGE e segundo dados fornecidos pela Prefeitura Municipal, foi calculada a densidade demográfica para os bairros do município. A média encontrada (para 2010) foi de $914 \mathrm{hab} . / \mathrm{km}^{2}$. Os dados por bairro podem ser conferidos na Tabela 01, onde percebe-se grandes diferenças entre uma área central mais consolidada, sua periferia imediata e um amplo grupo de bairros periféricos com baixíssimas densidades.

Tabela 01 - Estimativa de densidade por bairros conforme censo 2010.

\begin{tabular}{|l|r|r|r|}
\hline Bairro & Habitantes & \multicolumn{1}{|c|}{ Área $\left(\mathbf{k m}^{2}\right)$} & Densidade $\left(\mathbf{h a b} / \mathbf{k m}^{2}\right)$ \\
\hline Alto do Parque & 1.618 & 0,95 & 1702,39 \\
\hline Americano & 2.684 & 0,60 & 4452,17 \\
\hline Bom Pastor & 1.118 & 3,11 & 359,53 \\
\hline Campestre & 1.985 & 1,77 & 1119,85 \\
\hline Carneiros & 1.279 & 5,32 & 240,34 \\
\hline Centário & 1.704 & 1,00 & 1710,47 \\
\hline Centro & 7.055 & 1,43 & 4933,23 \\
\hline Conservas & 2.336 & 0,90 & 2593,92 \\
\hline Conventos & 3.423 & 15,15 & 225,96 \\
\hline Floresta & 500 & 3,32 & 150,71 \\
\hline Florestal & 4.999 & 1,00 & 5021,88 \\
\hline Hidráulica & 2.368 & 1,78 & 1331,60 \\
\hline Igrejinha & 936 & 1,91 & 490,47 \\
\hline Imigrante & 666 & 6,96 & 95,64 \\
\hline Jardim do Cedro & 3.692 & 2,07 & 1781,02 \\
\hline Moinhos & 5.528 & 2,72 & 2034,89 \\
\hline Moinhos d'Água & 2.152 & 3,95 & 545,30 \\
\hline Montanha & 4.000 & 2,02 & 1978,43 \\
\hline Morro 25 & 1.316 & 0,63 & 2099,10 \\
\hline Nacões & 584 & 0,59 & 997,58 \\
\hline Olarias & 2.195 & 1,77 & 1343,34 \\
\hline Planalto & 1.502 & 1,77 & 847,36 \\
\hline Santo André & 1.966 & 0,32 & 6158,50 \\
\hline Santo Antônio & 3.260 & 1,63 & 1995,12 \\
\hline São Bento & 1.525 & 9,34 & 163,21 \\
\hline São Cristóvão & 7.039 & 1,96 & 3583,54 \\
\hline Universitário & 3.750 & 3,91 & 959,02 \\
\hline Total & $\mathbf{7 1 . 1 8 0}$ & $\mathbf{7 7 , 8 8}$ & $\mathbf{9 1 3 , 9 2}$ \\
\hline
\end{tabular}

Fonte: Dos autores (2018), a partir de dados do IBGE (2010). 
A partir destes dados, pode-se classificar os bairros da cidade de Lajeado em três categorias principais quanto à densidade demográfica. O primeiro grupo abrange os bairros relativamente densos da cidade, que, apesar de distantes dos parâmetros indicados pelo CDBC (BUSCH; HARVEY; HE; HUANG, 2015) apresentam densidades superiores à média. Os bairros Americano, Centro, Florestal, Santo André e São Cristóvão compõem esta primeira divisão, com densidades a partir de $3.500 \mathrm{hab} . / \mathrm{km}^{2}$. São bairros localizados próximos ao centro de fundação da cidade, ou imediatamente contíguos aos eixos de crescimento observados desde os anos 1980 (GABE, 2017), que apresentam urbanização contínua, verticalização frequente (especialmente Centro, Americano e São Cristóvão) e parcelamento em grande parte ocupado com usos diversos.

Bairros como Alto do Parque, Campestre, Centenário, Conservas, Hidráulica, Jardim do Cedro, Moinhos, Montanha, Morro 25, Olarias, Santo Antônio e Universitário ocupam a segunda categoria quanto à densidade populacional, com valores entre 950 e $2.500 \mathrm{hab} . / \mathrm{km}^{2}$. Estes são os bairros da periferia próxima ao Centro, com urbanização relativamente contínua, mas ocupação parcial dos lotes parcelados. A verticalização ocorre em trechos dos eixos principais, a diversidade de usos é mais baixa, tendo usos não-residenciais com maior frequência nos trechos principais das vias estruturadoras.

Finalmente, os bairros com os menores índices (até 850 hab. $/ \mathrm{km}^{2}$ ), que se encontram muito distantes do ideal para o pleno funcionamento das infraestruturas urbanas são Bom Pastor, Carneiros, Conventos, Floresta, Igrejinha, Imigrante, Moinhos d'Água, Nações, Planalto e São Bento. Estes bairros respondem pela maior parte da expansão da mancha urbana recente, especialmente após a alteração do perímetro urbano em 1998 (GABE, 2017). São bairros com ocupação extremamente rarefeita, grande descontinuidade da malha urbana, baixa ocupação dos lotes parcelados e perfil majoritariamente horizontal com baixíssima diversidade de usos e atividades.

O primeiro quesito a ser debatido quanto ao conjunto de infraestruturas lajeadenses é o sistema público de transporte coletivo. Lajeado não possui Plano de Mobilidade e o Plano Diretor não contempla diretrizes para o transporte e, apesar de apontar para estratégia de eixos comerciais de alta densidade (com potencial de mais de 80.000 hab. $/ \mathrm{km}^{2}$ em algumas regiões), tem grades assimetrias na distribuição dos serviços prestados pelas duas empresas responsáveis pelo transporte coletivo urbano: a Ereno Dörr e a Scherer (GRUPO INDEPENDENTE, 2017).

A Imagem 02 apresenta a sobreposição das áreas ocupadas da cidade com a mancha das áreas a 300m das linhas de ônibus existentes no município. Observa-se que, para os bairros relativamente densos, há atendimento integral à demanda pelo serviço. Nestes bairros a volta do Centro, em média $70 \%$ das moradias são atendidas pelo transporte público (BIOSSPLENA, 2017). 
Imagem 02 - Moradias próximas ao transporte coletivo em Lajeado/RS

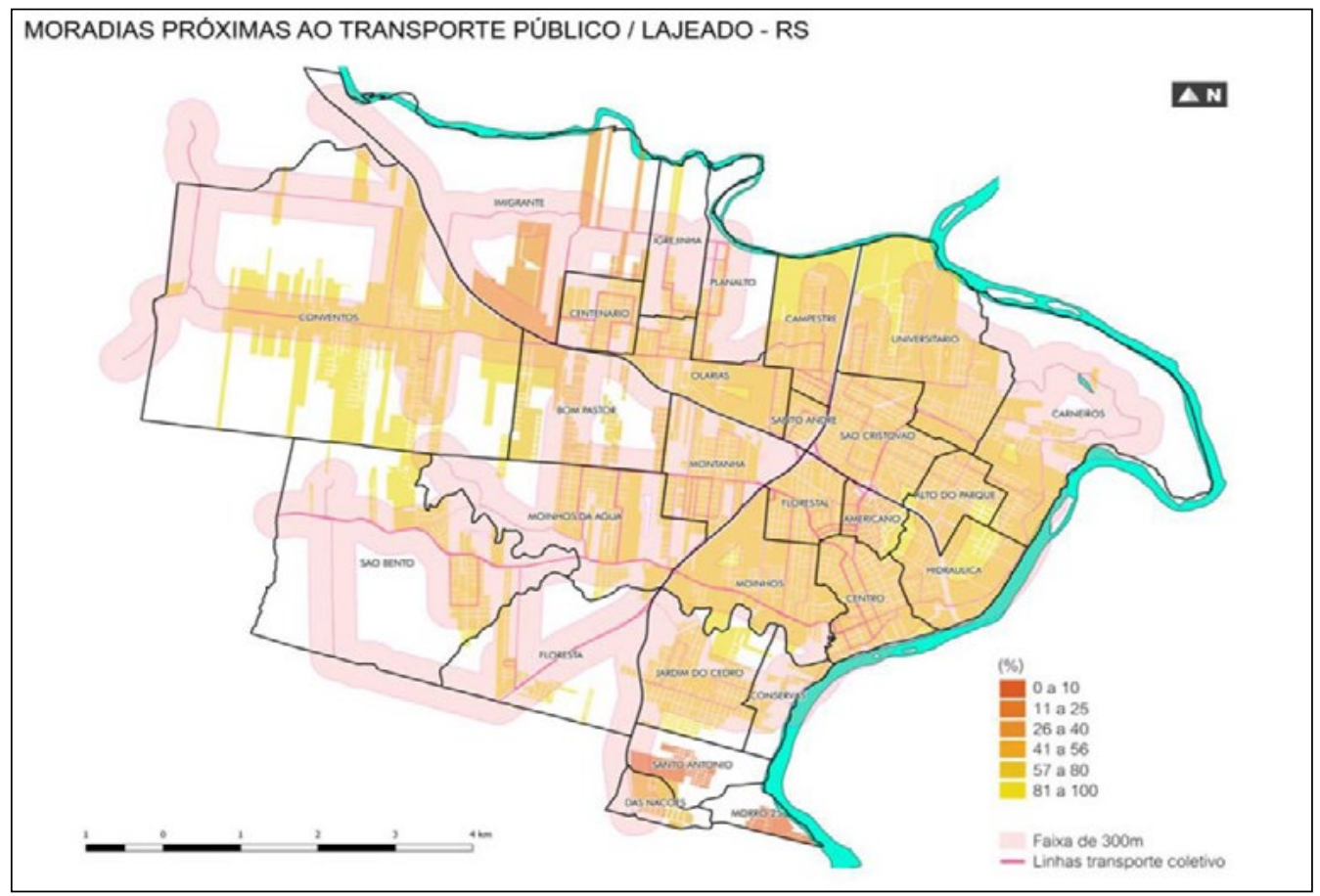

Fonte: Biossplena (2017).

Para os bairros da periferia central - o segundo grupo na escala demográfica de Lajeado - nota-se que as linhas disponibilizadas ainda são suficientes para a maior parte da população. Contudo, nessa categoria, já há locais que possuem apenas até 10\% de moradias próximas às linhas e paradas de transporte coletivo, como é o caso dos bairros Santo Antônio e Morro 25. Estes são justamente os bairros mais pobres da cidade (junto com bairro Igrejinha), onde se localizam diversos conjuntos de habitação de interesse social e população com grande dependência do transporte coletivo.

Finalmente, para os bairros mais dispersos da cidade são ofertadas algumas opções de itinerários, que são, em termos gerais, adequados, uma vez que a urbanização ocorre ao redor dos eixos viários principais. No entanto, devido às baixas densidades, a frequência do transporte coletivo é muito inferior aos bairros mais populosos, ocasionando tempos de espera longos.

Fica nítido que estes locais de baixíssima densidade ocasionam o encarecimento da rede de transporte devido a sua extensão. Uma vez que as linhas de ônibus percorrem longos trajetos sem que haja passageiros suficientes para manter o sistema economicamente viável e eficiente, diminuem a qualidade do serviço prestado e impactam a tarifa para todos os usuários do 
sistema. Indício dessa ineficiência é a crise recente das empresas de ônibus, que têm dificuldades em manter a frota de veículos funcionando.

O Departamento de Trânsito do Rio Grande do Sul relata redução de 30\% no número de passageiros entres os anos de 2016 e 2017 (GRUPO INDEPENDENTE, 2017). Com esta queda nos usuários da modalidade, a tarifa cobrada pelas empresas foi reajustada acima da inflação no ano de 2017, de modo a evitar prejuízos no curto prazo, mas possivelmente diminuindo o número de usuários a médio.

Além disso, a proporção da população usuária do modo coletivo de transporte é de cerca de 6 mil pessoas, 7,23\% do total. Esta baixa procura, em última análise, ocasiona seu mau funcionamento: há baixa frequência, poucas opções de horários e inclusive registros de descumprimento de horários e esquecimento de usuários nas paradas (GRUPO INDEPENDENTE, 2017).

Avaliando-se a sua inserção urbana (LABCIDADE/USP; ITDP, 2014), os bairros com densidades a partir de 3.500 hab. $/ \mathrm{km}^{2}$ em Lajeado estão bem servidos quanto à quantidade de linhas e diversidade dos itinerários. Conforme avança-se em direção às periferias, decresce a qualidade dos serviços de transporte urbano prestados. A porção Oeste de Lajeado é a mais expressiva quanto à falta de atendimento das linhas de ônibus. No bairro Conventos, há habitações registradas distantes a mais de um quilômetro da circulação do transporte coletivo. A ineficiência e baixa frequência das rotas pode ainda ser identificada na Imagem 02. Há linhas em locais onde não há habitações registradas, servindo apenas como conexões entre dois pontos. O problema é que essas rotas extensas encarem o sistema, promovem o aumento do tempo de permanência nos veículos coletivos e desincentivam o uso do transporte de massas.

Em conjunto com estas dificuldades do transporte coletivo, observa-se um grande aumento na frota de veículos particulares na última década. Segundo o DETRAN (2018), há 36.937 automóveis e 12.781 motocicletas circulando na cidade, um aumento de $2,59 \%$ em relação à frota do ano anterior. Conforme estes dados, pode-se afirmar que aproximadamente $60 \%$ dos moradores lajeadenses possuem acesso ao transporte privado, taxa maior que os $42 \%$ da população economicamente ocupada (IBGE, 2018).

Outro parâmetro que convêm ser abordado é a urbanização das vias públicas no município. O quesito abrange a presença de bueiros, calçadas, pavimentação e meio fio. O índice para a cidade de Lajeado acerca destes aspectos é de apenas 44,1\% das vias, segundo o IBGE (2017).

Observa-se que quanto maior a renda per capita dos moradores, mais frequente é a presença de infraestrutura completa nas vias. No entanto, há desigualdade na distribuição destas infraestruturas, uma vez que para habitantes com renda de um quarto a meio salário mínimo observam-se vias 
frequentemente desprovidas de iluminação pública, rampas para cadeirantes, pavimentação, arborização, calçada e meio fio.

Quanto à pavimentação, a Imagem 03 demonstra que a maior concentração das vias pavimentadas se dá nos bairros mais densos, próximos ao centro da cidade (PREFEITURA MUNICIPAL DE LAJEADO, 2017). Os cinco bairros mais populosos também detêm vias mais adequadas, com presença de meio-fio e passeios apropriados, na maior parte de sua extensão.

Imagem 03 - Pavimentação em Lajeado/RS

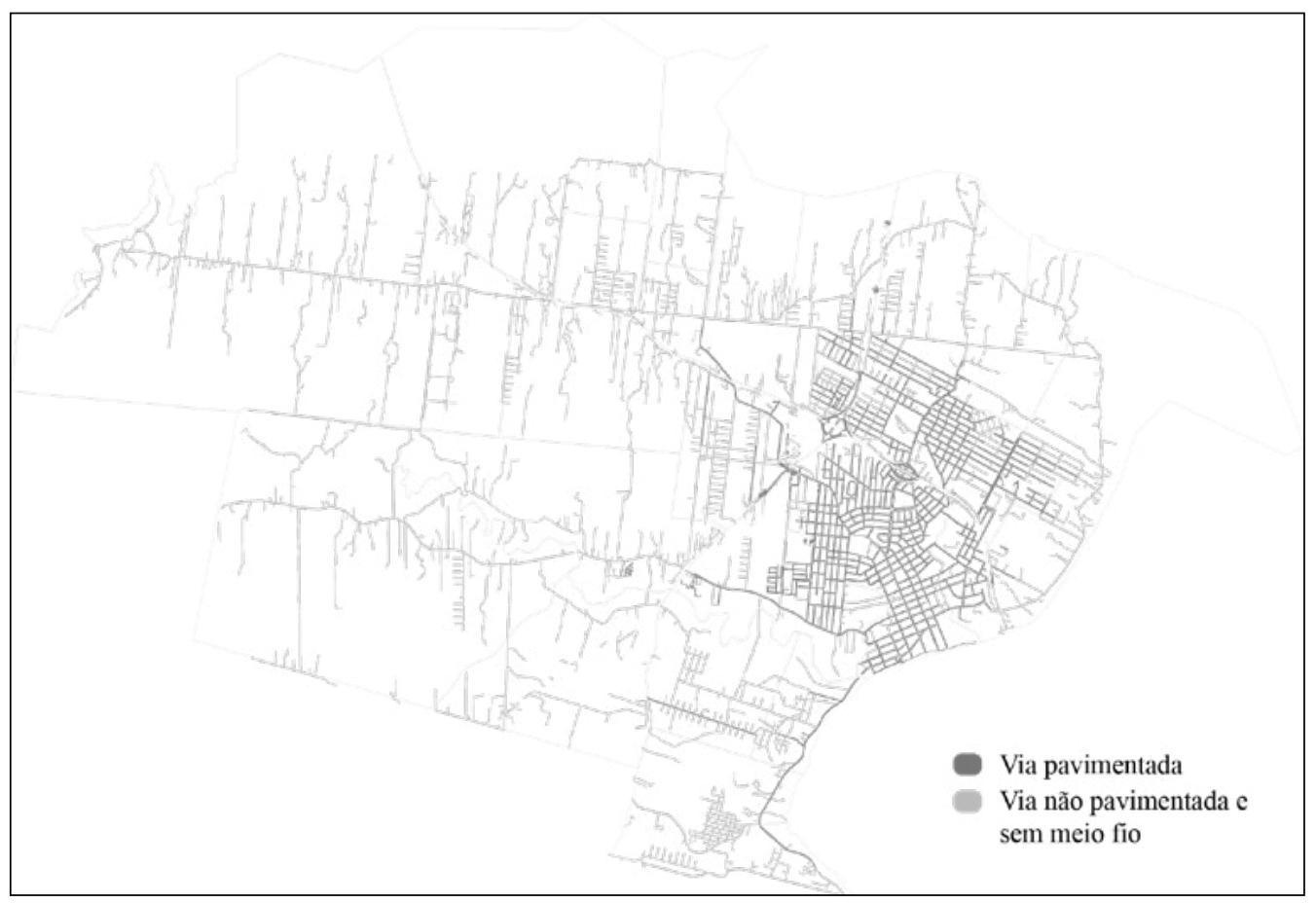

Fonte: Dos autores, com base nos dados de Prefeitura Municipal de Lajeado (2017).

Observa-se também que os bairros de densidade média (entre 950 e $2.500 \mathrm{hab} . / \mathrm{km}^{2}$ ) possuem as vias de principais acessos pavimentadas, enquanto que as de uso local variam de bairro para bairro. O bairro Alto do Parque, por exemplo, é guarnecido de pavimentação em todas suas ruas, enquanto que no bairro Montanha esse índice é bem mais baixo.

Por último, os bairros mais periféricos apresentam uma malha urbana com crescimento linear, que acompanha as poucas vias principais. Este fenômeno fica nítido principalmente nos bairros Conventos e São Bento, cuja urbanização depende das avenidas Pedro T. Breidenbach e Carlos Spohr Filho, respectivamente, como demonstra a Imagem 02. Esta lógica de crescimento estimula grandes deslocamentos e não otimiza o investimento em infraestrutura 
adequada, ampliando o uso ineficiente dos espaços urbanos. Nestes bairros, as vias que se desenvolvem a partir dos eixos principais não apresentam infraestruturas completa, mantendo, em muitos locais, seu aspecto rural.

Imagem 04 - Iluminação pública e bueiros em Lajeado/RS

Poste de iluminação pública

Fonte: Dos autores, com base nos dados de Prefeitura Municipal de Lajeado (2017).

A mancha de iluminação pública formada no tecido urbano também ilustra as áreas de maior concentração humana na cidade. A região Leste onde estão localizados o Centro e bairros mais densos - é provida de maior infraestrutura no quesito iluminação. Centro, São Cristóvão, Americano, Florestal, Santo André e Alto do Parque possuem a maior superfície iluminada do município. Isso pode ser explicado pelo fato do investimento na infraestrutura seguir o valor do solo, conforme descrito por Villaça (2011).

De forma geral, é possível afirmar que a cidade apresenta diferenças internas importantes na distribuição das infraestruturas indispensáveis. Apesar de ocupar o $64^{\circ}$ lugar em urbanização adequada de vias públicas no estado, observa-se diferença marcada entre as três categorias de densidade propostas, com médias muito mais baixas para os bairros menos densos. 


\section{CONSIDERAÇÕES FINAIS}

O mapeamento do sistema de infraestruturas da cidade de Lajeado se fez necessário para compreender a sua distribuição entre todos os vinte e sete bairros do município. Ficou nítido que as infraestruturas analisadas transporte, qualidade do sistema viário e iluminação - estão ou nas áreas com o maior número de moradias por quilômetro quadrado, ou nas regiões mais valorizadas pelo mercado imobiliário.

A categorização dos bairros de Lajeado em três grupos distintos mostrou correlação com as infraestruturas instaladas, corroborando expectativas de que os bairros mais densos tenham melhor qualidade de infraestrutura e permitindo caracterizar melhor a urbanização lajeadense. Percebeu-se, porém, algumas variações ocorridas entre os bairros, principalmente no transporte coletivo, em que, apesar da boa distribuição da maior parte de itinerários de transporte público, há concentração clara nas áreas de maior densidade.

É importante ressaltar que há um padrão recente de crescimento linear e descontinuo do tecido urbano. Nestes casos, há o desenvolvimento a partir de uma via principal de um bairro, com baixíssima conectividade das demais. Enquanto nas vias principais existe pavimentação e concentram-se os usos comerciais, nas vias secundárias há uma queda drástica na qualidade da urbanização e na ocupação dos lotes já parcelados. Como impacto, este modelo demanda maior extensão da infraestrutura urbana, encarecendo os serviços e minimizando sua qualidade, assim como diminuindo a atratividade da urbanização, como observa Krafta (1999).

A partir destas considerações, percebe-se que Lajeado está incluída na descrição de cidades tipicamente brasileiras feita por Abramo (2001) e Malenronka (2018). Nestas caracterizações do desenvolvimento urbano, o tecido urbano da região central e imediações possui malha mais densa e ocupada, atendida por um sistema mais adequado de infraestruturas urbanas, enquanto as periferias ou são precárias, ou têm soluções privadas de auto segregação. Estas disparidades populacionais, como já apontado por Reis Filho (2012), acarretam em problemas sociais e econômicos, principalmente para os bairros que possuem menor renda per capita, como o Santo Antônio, Morro 25 e Igrejinha, no caso de Lajeado.

Além de elevar custos, a extensão de obras de infraestruturas provocadas pelas malhas urbanas descontínuas de Lajeado dificulta o acesso ao transporte coletivo e reduz sua eficiência e qualidade, conforme observa Sposito (2014) para outros casos do país. Deve-se observar que essa dispersão altera a distribuição dos usos na cidade, influenciando a economia e as relações sociais a longo prazo.

As duas dimensões de dispersão trazidas por Ojima e Marandola (2016) são nítidas em Lajeado. O crescente número de condomínios fechados em bairros de baixa densidade (como São Bento e Conventos) ou média (Universitário, por 
exemplo) indica que o transporte privado propicia a auto segregação a esses moradores, visto que os mesmos conseguem se deslocar até seus empregos ou o polo comercial da cidade, por exemplo, sem maiores dificuldades.

Contudo, há também a periferização imposta a pessoas de baixa renda, que só conseguem custear terrenos em locais mais distantes do centro. Os condomínios de habitação de interesse social existentes em Lajeado, Novo Tempo I e II, por exemplo, retratam um aumento na densidade populacional sem investimentos em infraestruturas indispensáveis. Para o empreendimento, foram construídos 28 edifícios capazes de abrigar quase 450 famílias (Prefeitura Municipal de Lajeado, 2015) em localização que dificultou o acesso das famílias à equipamentos urbanos essenciais, como posto de saúde, escola, mercado e outros, que são consolidados nas áreas centrais.

Tanto a auto segregação, quando a periferização restringem também o uso do transporte coletivo, seja por falta de linhas com frequência adequada (no caso dos bairros mais populosos), ou por falta de procura ao sistema por parte dos moradores (nos condomínios fechados). Ressalta-se que são problemas oriundos da fragmentação da malha urbana, que levam, em geral, a diminuição das caminhadas ou exercícios físicos diários (GARDEN; JALALUDIN, 2009) e a maiores despesas com saúde pública (AMARO, 2016).

Outro impacto a destacar é o impacto da frota de veículos particulares no meio ambiente, que é cada vez mais contaminado pelos gases oriundos da queima do combustível. Estes efeitos poderiam ser minimizados a partir dos sete princípios guia do DOTS: a viabilização do transporte público de qualidade, com mais oferta de viagens convenientes; o incentivo à mobilidade não motorizada; a racionalização no uso do automóvel; a implantação de edificações com uso misto com o pavimento térreo comercial; a qualificação dos espaços públicos, promovendo atividades nos centros de bairros; a readequação de espaços públicos e recursos naturais; e por fim a valorização da identidade comunitária somada à participação de diferentes grupos socioeconômicos no mesmo ambiente (DOTS, como definido pelo WRI em EVERS et al., 2018). No entanto, estes princípios dependem, intensamente, da gestão da expansão do território urbano, uma vez que os custos de transporte são diretamente impactados pela densidade demográfica.

\section{CONCLUSÃO}

A partir de observações sobre a realidade de Lajeado/RS e das bases teóricas referidas, pode-se afirmar que a cidade em análise é caracterizada como dispersa. Desde os anos 2000 a fragmentação da sua forma urbana tem se acelerado em dois comportamentos: densificação das áreas centrais mais valorizadas e já infraestruturadas e a expansão horizontal e descontinua das periferias afastadas. Ao cotejar estes padrões com as infraestruturas implantadas, observa-se perda de qualidade e aumento das descontinuidades, 
potencialmente ampliando custos e ineficiência geral dos sistemas. Tanto por este quesito financeiro, quanto devido aos impactos ambientais e na saúde dos habitantes, há fortes indícios da insustentabilidade destes padrões a longo prazo.

A alternativa apontada por grande parte da literatura é a adoção de modelos compactos de desenvolvimento (MONTEIRO, 2015; EVERS et al., 2018), especialmente o DOTS. Para que Lajeado possa adotar estas recomendações é necessário que haja um "maior controle dos novos empreendimentos, um maior incentivo para reuso do solo construído nas áreas mais centrais das cidades" (MONTEIRO, 2015, p.129).

No entanto, considerando as limitações desta reflexão, se faz necessário aprofundamento na correlação entre transporte público e renda, para melhor compreensão dos impactos da distribuição, frequência e disponibilidade do serviço de ônibus. É notável que para o cumprimento das recomendações do DOTS deve-se ampliar o uso dessa modalidade de locomoção a pessoas de classe socioeconômica média, oportunizando às mesmas uma opção qualificada ao uso do transporte individual.

A partir destas considerações iniciais sobre transportes e infraestrutura viária, observa-se grande potencial de análise nos estudos das demais infraestruturas, da rede de distribuição de água, no sistema de tratamento de esgoto e na transmissão de energia nos bairros da cidade de Lajeado, não abordados no presente artigo, mas importantes ao entendimento da distribuição de infraestruturas ao decorrer dos vinte e sete bairros e na forma como impactam o cotidiano dos moradores.

Finalmente, a forma como o Plano Diretor de Desenvolvimento Integrado (PDDI) estabelece diretrizes de controle de ocupação urbana e as suas implicações quanto à dinâmica demográfica para os bairros da cidade também são pautas pertinentes. Neste sentido, a correlação dos padrões de crescimento, de parcelamento do solo, das densidades demográficas e das infraestruturas devem ser objeto de reflexões mais aprofundadas. Observa-se possíveis contribuições para as revisões do Plano Diretor em curso atualmente, afinal, trazer mais eficiência ao uso das infraestruturas e serviços públicos é pauta central para a sustentabilidade da qualidade da urbanização no município e a relação entre estes serviços e a densidade de ocupação é dos elementos mais críticos para esta pauta.

\section{REFERÊNCIAS}

ABRAMO, P. A cidade caleidoscópica. Rio de Janeiro: Editora Bertrand, 2001.

ACIOLY, C.; DAVIDSON, F. Densidade urbana: um instrumento de planejamento e gestão urbana. Rio de Janeiro: Mauad, 1998. 
AMARO, A. B. O processo de dispersão urbana e a questão ambiental: uma comparação da literatura estrangeira com o fenômeno no Brasil. Revista Formação (Online), 2016.

BIOSSPLENA. Indicadores de desenvolvimento urbano. Flores da Cunha: Biossplena Inteligência Urbana, 2017. Disponível em <http:/ / biossplena.com.br/indicadores-dedesenvolvimento-urbano-lajeado-rs-2017-7-800-ha>. Acesso em 20 nov. 2018.

BOTELHO, A. Capital volátil, cidade dispersa, espaço segregado: algumas notas sobre a dinâmica do urbano contemporâneo. Cadernos Metrópole. São Paulo, 2012.

BRUEGMANN, R. La dispersión urbana: una historia condensada, Madrid: Comunidad de Madrid Publicaciones Oficiales, 2005.

BUSCH, C.; HARVEY, H.; HE, D.; HUANG, C. 12 Green Guidelines: CDBC's green and smart urban development guidelines. Beijing: China Development Bank Capital, 2015. Disponível em < http:/ /cdn.plataformaurbana.cl/wp-content/ uploads /2016/02/12-principios-de-diseno-urbano-sustentable-banco-desarrollochina-fundacio\%CC\%81n-energia-china.compressed.pdf>. Acesso em 29 nov. 2018.

CALDEIRA, T. P.do R. Enclaves Fortificados: a nova segregação urbana. Novos Estudos Cebrap, Rio de Janeiro, p. 155-176, 1997.

DETRAN. Frota do RS. Departamento de Trânsito do Rio Grande do Sul, 2018. Disponível em <http:/ / www.detran.rs.gov.br/conteudo/27453/frota-do-rs>. Acesso em 27 nov. 2018.

ENGELS, F. A situação da classe trabalhadora em Inglaterra. Porto: Afrontamento, 1975.

EVERS, H. et al. DOTS nos Planos Diretores: Guia para inclusão do Desenvolvimento Orientado ao Transporte Sustentável no Planejamento Urbano. Porto Alegre: World Resource Institute, 2018.

GABE, M. Flexibilização do perímetro urbano e suas repercussões sobre a expansão urbana: estudo de Lajeado/RS (1984-2016). 2017. Universidade Federal do Rio Grande do Sul, Porto Alegre, 2017.

GARDEN, F. L.; JALALUDIN, B. B. Impact of urban sprawl on overweight, obesity, and physical activity in Sydney, Australia. In Journal of Urban Health, v. 86, n. 1, p. 19-30, 2009.

IBGE. Censo demográfico: resultado do universo. Rio de Janeiro: Instituto Brasileiro de Geografia e Estatística, 2010.

IBGE. Panorama da população. Rio de Janeiro: Instituto Brasileiro de Geografia e Estatística, 2017. 
IBGE. IBGE I Cidades I Rio Grande do Sul. Rio de Janeiro: Instituto Brasileiro de Geografia e Estatística, 2018. Disponível em: <http:/ / www.cidades.ibge.gov.br/ download/ mapa_e_municipios.php?lang=\&uf=rs>. Acesso em: 28 nov. 2018.

JANOSCHKA, M. El nuevo modelo de la ciudad latinoamericana: fragmentación y privatización. EURE (Santiago), v. 28, n. 85, p. 1-14, 2002.

KRAFTA, R. Análise espacial urbana: aplicações na RMPA. Porto Alegre: Ed. UFRGS, 2009.

LABCIDADE/USP; ITDP. Ferramenta de avaliação de inserção urbana para os empreendimentos de faixa 1 do programa Minha Casa Minha Vida. Rio de Janeiro: LabCidade/USP; Instituto de Políticas de Transporte e Desenvolvimento, 2014. Disponível em: <http:/ /itdpbrasil.org.br/ferramenta-de-avaliacao-de-insercaourbana $>$ Acesso em 20 out. 2018.

LEE, B. "Edge" or "Edgeless" Cities? Urban Spatial Structure in U.S. Metropolitan Areas, 1980 To 2000*. Journal of Regional Science, v. 47, n. 3, p. 479-515, 2007.

MALENRONKA, C. Cidade compacta, cidade dispersa: entenda o que é a forma urbana. The City Fix Brasil, São Paulo, 10 de janeiro de 2018. Disponível em <http:/ / thecityfixbrasil.com/2018/01/10/cidade-compacta-cidade-dispersa-entenda-o-que-ea-forma-urbana/>. Acesso em 15 out. 2018.

MONTEIRO, F. M. A Cidade não para, a cidade só cresce: Análise do processo de dispersão urbana e impacto na dinâmica populacional. Dissertação (Mestrado em Demografia) Universidade Federal do Rio Grande do Norte. UFRN. Natal, 2015.

MOURA, R. M. G. R. Habitação popular em Pelotas (1880-1950): entre políticas públicas e investimentos privados. Tese (Doutorado em História) - Faculdade de Filosofia e Ciências Humanas, Pontifícia Universidade Católica do Rio Grande do Sul, Porto Alegre, 2006

NASCIMENTO JÚNIOR, L. Urbanização e cidade dispersa: implicações da produção do espaço urbano no Brasil, em Moçambique e na Austrália. GeoUSP - Espaço e Tempo (Online), v. 21, n. 2, p. 550-569, agosto. 2017. ISSN 2179-0892.

NETTO, V. M. A cidade como resultado: consequências de escolhas arquitetônicas. In: BALBIM, R.; KRAUSE, C.; LINKE, C. C. (Eds.). Cidade e Movimento: mobilidades e interações no desenvolvimento urbano. Brasília, D.F.: IPEA; ITDP, 2016. p. 102-130.

NETTO, V. M.; VARGAS, J. C.; SABOYA, R. T. (Buscando) Os efeitos sociais da morfologia arquitetônica. urbe. Revista Brasileira de Gestão Urbana, Curitiba, v. 4, n. 2, p. 261-282, 2012.

OJIMA, R.; MARANDOLA JR., E. (Org.). Dispersão urbana e mobilidade populacional: implicações para o planejamento urbano e regional. São Paulo: Blucher, 2016. 
PARESI, M.; MELCHIORRI, M.; SIRAGUSA, A.; KEMPER, T. Atlas of the Human Planet 2016: Mapping Human Presence on Earth with the Global Human Settlement Layer. Ispra: JRC Science Hub, 2016.

PASSAGEM de ônibus sobe para $\mathrm{R} \$ 3,70$ a partir desta segunda feira, em Lajeado. Grupo Independente. Lajeado, 07 abr. 2017. Disponível em < http:/ /independente. com.br/passagem-de-onibus-sobe-para-r-370-a-partir-de-segunda-feira-em-lajeado/>. Acesso em 28 nov. 2018.

PREFEITURA MUNICIPAL DE LAJEADO. Base de dados cartográficos de LajeadoRS. Lajeado: Prefeitura Municipal de Lajeado, 2017.

REIS, N. G. Notas sobre urbanização dispersa e novas formas de tecido urbano. 1a. ed. São Paulo: Via das Artes, 2006.

REIS FILHO, A. A. Análise integrada por geoprocessamento da expansão urbana de Teresina com base no Estatuto da Cidade: Estudo de potencialidades, restrições e conflitos de interesses. 2012. Tese (Doutorado em Geografia), Universidade Federal de Minas Gerais. UFMG. Belo Horizonte. 2012

SANTOS, A. P.; POLIDORI, M. C.; SARAIVA, M. V. P.; PERES, O. M. O lugar dos pobres nas cidades: exploração teórica sobre periferização e pobreza na produção do espaço urbano Latino-Americano. urbe. Revista Brasileira de Gestão Urbana, Curitiba, v. 9, n. 3, p. 430-442, 2017.

SILVA, E. T. Estrutura urbana e mobilidade espacial nas metrópoles. Rio de Janeiro: Letra Capital, 2013.

SMITH, T.; DOHERTY, M. The suburbanization of coastal Australia. Canberra: Australia State of the Environment Committee/Department of Environment and Heritage, 2006.

TANSCHEIT, P. Cidades compactas e o difícil equilíbrio entre densidade e verticalização. The City Fix Brasil, São Paulo, 3 de agosto de 2016. Disponível em: <http:/ / thecityfixbrasil.com/2016/08/03/cidades-compactas-e-o-dificil-equilibrioentre-densidade-e-verticalizacao/>. Acesso em: 15 nov. 2018.

VARGAS, J. C. Densidade, paisagem urbana e vida da cidade: jogando um pouco de luz sobre o debate porto-alegrense. Arquitextos (Vitruvius), Rio de Janeiro, n. 039.07, 2003. Disponível em: http:/ / www.vitruvius.com.br/revistas/read/ arquitextos /04.039/663

VILLAÇA, F. São Paulo: segregação urbana e desigualdade. Estudos Avançados, São Paulo, v. 25, n. 71, p. 37-58, 2011. 